\title{
INFLUENCE OF NANOFIBER LOADING AND MOULDING CONDITIONS ON THE JOINING STRENGTH OF THERMOPLASTIC COMPOSITES FABRICATED BY INJECTION OVER-MOULDING PROCESS
}

\author{
KOKI MATSUMOTO ${ }^{1 *}$, TUKASA NAGASAKA ${ }^{1}$, KENICHI TAKEMURA $^{1} \&$ TATSUYA TANAKA $^{2}$ \\ ${ }^{1}$ Department of Mechanical Engineering, Kanagawa University, Japan \\ ${ }^{2}$ Department of Energy and Mechanical Engineering, Doshisha University, Japan
}

\begin{abstract}
An over-moulding process has promised a novel technology for joining lightweight thermoplastic composites with metal or polymer composite parts. Specifically, the substrate parts (metal or textile composites) are put into a mould of the injection moulding machine and melt polymer is injected onto substrate parts. This over-moulding process provides great benefits in terms of fast welding and moulding at the same time. However, the interfacial joining strength of over-moulded parts is still unreliable, and it has a strong dependence on surface treatment of substrate and moulding conditions. The key topic of this joining process is to achieve a reliable joining strength. In this study, we focused on using cellulose nanofiber $(\mathrm{CNF})$ to interconnect between substrate and injection part by purpose of mechanical interlocking in nanoscale. Furthermore, joining strength was determined by single-lap shear test to examine the effect of presence of nanofiber. The single-lap joint consists of plain weave carbon fibre (CF) reinforced polypropylene (PP) composites (CFRPP) as substrate part and pure PP as overinjection polymer. To place the cellulose nanofiber at the interface, $\mathrm{CF}$ wovens and PP sheets were stacked alternately, and CNF contained PP sheet was placed at outer layer. The CFRPP substrate was obtained by heating press, pure PP was injected onto the substrate at the side of presence of CNF. This study was investigated on the influence of process conditions (i.e., injection temperature and runner route) and CNF content ratio (up to $3.0 \mathrm{wt} \%$ ) on the shear strength as joining strength. Furthermore, the fracture morphology was observed through scanning electron microscope (SEM).

Keywords: over-moulding process, cellulose nanofiber, lightweight hybrid composite, single-lap shear.
\end{abstract}

\section{INTRODUCTION}

In the automotive industry, applying a lightweight structure with excellent mechanical properties is most important approach to reduce the environmental load. Thereby, a demand of carbon fibre (CF) reinforced thermoplastic composites (CFRTPs) has increased every year for mass production due to high mechanical property, recyclability and high productivity. Especially, for purpose of replacing metals to polymer composites, multi-material design by joining of different materials (e.g., CFRTPs and metals) is a new concept to meet the strict environmental regulations [1]-[4]. Furthermore, the combination of plastic processing technologies (e.g., injection moulding, extrusion process, and 3D printing) makes possible to manufacture lightweight design of hybrid CFRTPs with complex shape parts [5]-[11]. Therefore, a lot of thermal joining processes (laser welding [12]-[14], friction welding [15], ultrasonic welding [16] and injection over-moulding [17]-[20]) have been developed for joining thermoplastic composites with other materials.

In injection over-moulding process, direct joining of different components and forming of complex shape could be done at the same time. A substrate parts (e.g., metal parts and CFRTPs) are inserted into the mould of injection moulding machine, and subsequently the

*ORCID: https://orcid.org/0000-0002-4220-7304 
melt polymer is injected onto the substrate parts [5]. Direct joining could reduce the weight due to absence of mechanical fasteners (e.g., screws, blots and rivets) and adhesives. In any case, the most important key of over-moulding process is to achieve a reliable joining strength. In a polymer metal hybrids (HPM), the roughness of metal surface is controlled to mechanically interlock the joining interface. Lucchetta et al. [17] were applied shot peening on the surface of Aluminium (Al) 6082, and glass fibre reinforced polypropylene (PP) was injected onto the $\mathrm{Al}$ part. The combination of mechanical interlocking by surface roughness and anchor role by glass fibres could enhance the lap-shear strength. Kimura et al. [18], [19] formed nano-porous structure on the surface of A $5052 \mathrm{Al}$ by chemical etching process, and glass fibre reinforced polybutylene terephthalate (PBT) was moulded onto Al substrate part. They reported nanometer-scale structure enables to increase lap-shear strength by compared with micrometer-scale structure. Even though the surface roughness and nanopatterns [21] enhance the joining strength, the moulding conditions (e.g., injection speed, holding pressure, and resin temperature) have great influence on that.

Furthermore, hybrid thermoplastic composites can be manufactured by combination of continuous fibre reinforced composites and discontinuous fibre reinforced composites through injection over-moulding process. An organosheet, which thermoplastic resin is impregnated into continuous fibre or plain weave fabric, is pre-heated before inserting in the mould of injection moulding. The pre-heated organosheet was thermoformed during closing the mould, and short fibre reinforced thermoplastics injected onto thermoformed part to fabricate the hybrid composites. The joining strength is strongly affected by preheating conditions and moulding conditions [5], [10]. However, only the optimization of these processing parameters can enhance the joining strength. Therefore, new approach is necessary to be a reliable joining strength for hybrid thermoplastic composites without limitation of resin system and injection moulding system.

In the nano-engineered composites (i.e., multiscale composites), Garcia et al. [22] and Wicks et al. [23] focused on grafting carbon nanotubes (CNTs) on the CFs in the radial direction along the fibre. Epoxy resin is reinforced by CNT grafted CF wovens and its interlaminar shear strength (ILSS) was improved by $69 \%$. Veedu et al. [24] reported fracture toughness, mechanical properties, damping property and thermal conductivity of the composite were strongly improved by grafted CNT on CF. Adding of functional nanofiller at conventional textile composite provides some functional properties at low contents of nanofillers. Furthermore, Matsumoto et al. [25] added the CNTs at joining interface between organosheet and injection polymer through injection over-moulding process. Even though the dispersion state of CNTs affected on joining strength, the ILSS was increased up to $52 \%$ by adding CNTs of $1 \mathrm{wt} \%$. This means the nanotubes have ability to interconnect the different layers. However, there is a few reports of using nanofillers on application for joining technologies.

In this study, we newly attempt to use cellulose nanofibers (CNFs) on joining technologies, especially for hybrid thermoplastic composites through injection over-moulding process. CNFs have excellent mechanical properties and eco-friendly material. During fabrication of substrate parts which consist of CF wovens and PP films, CNFs filled PP sheet was placed at joining side. After impregnation and consolidation were finished during compression moulding, the substrate of CF woven reinforced PP composite (CFRPP) was obtained. Afterwards, CNF contained CFRPP substrate was inserted into the mould of injection moulding machine. The pure PP (without short fibres) was chosen as injection polymer to evaluate the simply effect of CNFs on joining strength. Finally, pure PP was injected onto the substrate part at side of presence of CNFs, and moulded specimens are obtained as singlelap joints. The joining strength was determined by single-lap shear test. In this paper, the 
influence of moulding conditions (i.e., barrel temperature and runner route) and CNF loading (up to $3 \mathrm{wt} \%$ ) on lap-shear strength was investigated. Moreover, fracture morphology was observed through scanning electron microscope (SEM) to discuss the interconnection role of CNFs.

\section{EXPERIMENTAL PROCEDURES}

\subsection{Materials}

Plain weave CF (Torayca ${ }^{\circledR}$ cloth type CO6343) was purchased from Toray Industries Inc., Japan and PP (Prime Polypro ${ }^{\mathrm{TM}}$ type $\mathrm{J} 107 \mathrm{G}$ ) was purchased from Prime Polymer Co. Ltd, Japan. The PP is homopolymer and a melt flow rate is $30 \mathrm{~g} / 10 \mathrm{~min}\left(230^{\circ} \mathrm{C}, 2.16 \mathrm{~kg}\right)$. A cellulose nanofiber (BiNFi-s type WFo-10005) was purchased from Sugino Machine Co. Ltd, Japan. The average diameter of this CNFs is approximately $10-50 \mathrm{~nm}$ and specific surface area is $120 \mathrm{~m}^{2} / \mathrm{g}$.

\subsection{Fabrication of single-lap joint}

At the beginning, a CNFs filled CFRPP substrates were fabricated. The CF woven sheets $(150 \mathrm{~mm} \times 150 \mathrm{~mm}$ size $)$ and pure PP or CNF filled PP (CNF/PP) sheets were prepared. The pure PP sheets and CNF/PP sheets were manufactured by heat press (Mini Test Press type MP-WCL) from Toyo Seiki Seisaku-Sho Ltd, Japan. Before compression of the nanocomposite lump that CNFs loading in weight were controlled by extruder, the lumps were pre-heated at $180^{\circ} \mathrm{C}$ for $4 \mathrm{~min}$. The pre-heated lumps were compressed at pressure of 3.0 $\mathrm{MPa}$ for $3 \mathrm{~min}$ at the same temperature, followed by cooling to $30^{\circ} \mathrm{C}$ rapidly. The thickness of obtained sheets was approximately $200 \mu \mathrm{m}$ and CNF loading set as $0 \mathrm{wt} \%$, $0.5 \mathrm{wt} \%, 1.0 \mathrm{wt} \%, 3.0 \mathrm{wt} \%$. After that, obtained seven pure PP sheets and seven CF woven sheets were stacked alternately, the CNF/PP sheets were placed at outer layer on only one side. The stack was pre-heated at $190^{\circ} \mathrm{C}$ for $10 \mathrm{~min}$ and compressed at pressure of $1.0 \mathrm{MPa}$ $\left(190^{\circ} \mathrm{C}, 15 \mathrm{~min}\right)$ while vacuuming air. The obtained CNF filled CFRPPs substrates had thickness of $3 \mathrm{~mm}$ and cut into small specimens (50 $\mathrm{mm}$ in length and $10 \mathrm{~mm}$ in width).

The fabrication of single-lap joint was conducted by injection moulding machine (type EC5P-0.1B) from Toshiba Machine Co. Ltd, Japan. The mould was originally self-designed for fabrication of the single-lap joint, and the runner route could be changed. The route A describes melt polymer flows into the opposite position of joining area. Other hands, the route B describes melt polymer flows from the joining area. The obtained substrate was inserted in the mould and pure PP was injected onto the substrate part at the side of presence of CNFs. The dimension of single-lap joint was described in Fig. 1(a), and moulded singlelap joint fabricated by each runner route was shown in Fig. 1(b). The dimension of substrate part and injection part was same and joining area was $12.5 \mathrm{~mm}$ in length and $10 \mathrm{~mm}$ in width. The moulding conditions are listed in Table 1. In this paper, two parameters (runner route and barrel temperature) were changed for fabricating specimens of single-lap joint. In addition, the barrel temperature was varied from $200^{\circ} \mathrm{C}, 220^{\circ} \mathrm{C}, 240^{\circ} \mathrm{C}, 260^{\circ} \mathrm{C}$.

\subsection{Single-lap shear test}

To evaluate the joining strength as lap-shear strength, tensile shear test was carried out by universal testing machine (type AG-IS) from Shimadzu Corporation, Japan. PP tabs (25 mm in length, $10 \mathrm{~mm}$ in width and $3 \mathrm{~mm}$ in thickness) were welded along the edge of specimen 


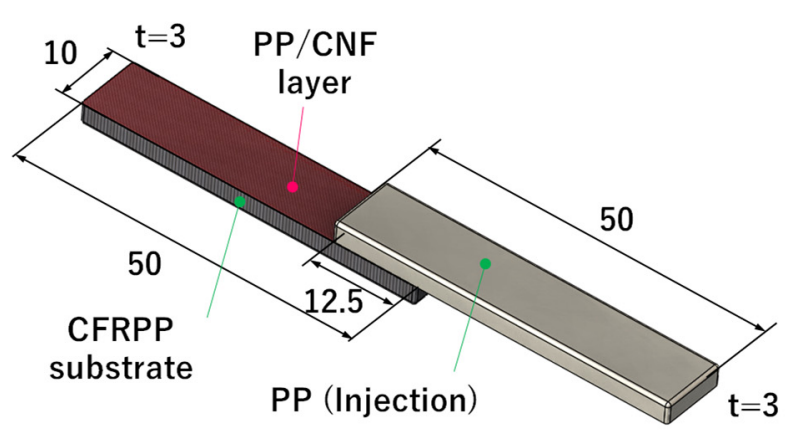

(a)

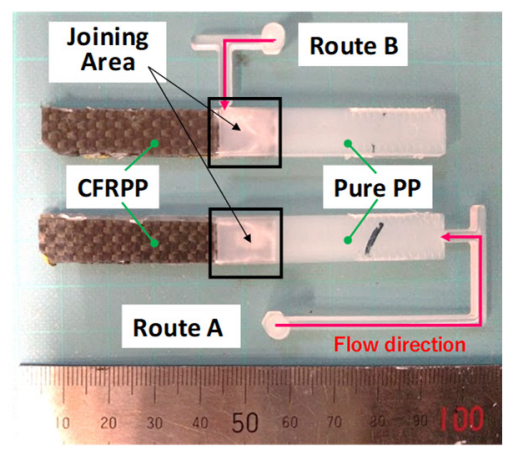

(b)

Figure 1: Single-lap joint. (a) A schematic drawing of specimen and dimension; and (b) Moulded specimens by changing runner route (lower: route A and upper: route $\mathrm{B})$.

Table 1: Moulding conditions of injection over-moulding.

\begin{tabular}{|c|c|c|c|c|}
\hline Process parameter & \multicolumn{4}{|c|}{ Set value } \\
\hline Runner route & \multicolumn{2}{|c|}{ Route A } & \multicolumn{2}{|c|}{ Route B } \\
\hline Screw speed (rpm) & \multicolumn{4}{|c|}{100} \\
\hline Injection speed $(\mathrm{mm} / \mathrm{s})$ & \multicolumn{4}{|c|}{30} \\
\hline Back pressure $(\mathrm{MPa})$ & \multicolumn{4}{|c|}{2.0} \\
\hline Barrel temperature $\left({ }^{\circ} \mathrm{C}\right)$ & 200 & 220 & 240 & 260 \\
\hline Mould temperature $\left({ }^{\circ} \mathrm{C}\right)$ & \multicolumn{4}{|c|}{60} \\
\hline Holding pressure (MPa) & \multicolumn{4}{|c|}{$40(1 \mathrm{st}) / 10(2 \mathrm{nd})$} \\
\hline Holding time (s) & \multicolumn{4}{|c|}{$15(1 \mathrm{st}) / 5(2 \mathrm{nd})$} \\
\hline Cooling time (s) & \multicolumn{4}{|c|}{20} \\
\hline
\end{tabular}

by soldering iron. The tensile shear test was conducted at a cross head speed of $1 \mathrm{~mm} / \mathrm{min}$ for three samples at each condition. The overview of tensile shear test was shown in Fig. 2. The lap-shear strength is obtained by dividing failure load by joining area.

\subsection{Observation of fracture morphology}

The fracture morphology was observed by using field emission scanning electron microscope (FE-SEM) (type S-4000) from Hitachi Ltd, Japan. The peeled surfaces of substrate and injection PP were mainly observed after lap-shear test. The peeled surfaces were coated by gold through sputtering system (Desk Top Quick Coater type SC-701MkII) from Sanyu Electron Co. Ltd, Japan. The state of CNFs at peeled surfaces was also observed.

\section{RESULTS AND DISCUSSION}

\subsection{Load-displacement curve of lap-shear test}

Before discussing effect of CNFs on lap-shear strength, the pure influence of process conditions was simply discussed here for the material system without CNFs. The load- 


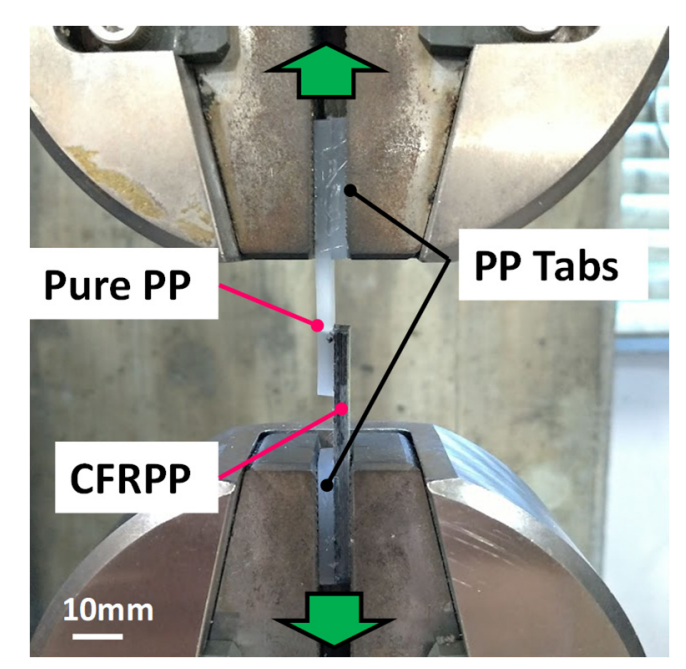

Figure 2: Over viewing of tensile shear test for specimen of single-lap joint.

displacement curves of lap-shear test and failure mode are shown in Fig. 3 (dotted area shows peeled position). Fig. 3(a) represents the influence of barrel temperature for the specimens which are moulded in runner route A, and Fig. 3(b) is for runner route B. As a reference material, PP injected into mould without insert substrate, it denotes as "all injected PP" in Fig. 3.

The "all injected PP" samples have no joining interface. Therefore, maximum of apparent shear strength of pure PP could be estimated. However, please note that the edge of lap joint rotates by bending moment and peel stress is caused [2], [4]. Therefore, the failure load of "all injected PP" samples does not indicate shear strength exactly. As the pictures of fracture mode are listed in Fig. 3, "all injected PP" samples were broken at step where thickness is changed due to stress concentration. The apparent shear strength of PP is only a guide for judging joining strength by injection over-moulding process was enough or not. The slope of load-displacement curve in "all injected PP" sample is lower than over-moulded samples. This explains that CFRPP has higher flexural modulus by compared with PP.

In this experiment, the condition of barrel temperature of $260^{\circ} \mathrm{C}$ and route $\mathrm{A}$ showed the highest failure load. In the influence of barrel temperature, failure load and displacement at break were increased with higher barrel temperature regardless of runner route. In the theory, welding should be done by diffusion of molecular chain between injection PP and PP layer of substrate. Therefore, molecular diffusion is affected by resin temperature at joining area during injection moulding. As shown in Fig. 3, the failure load of over-moulded specimens was smaller than that of "all injected PP" specimens even though barrel temperature is quite higher than melting temperature of PP (approximately $165^{\circ} \mathrm{C}$ ) with excepting condition at $260^{\circ} \mathrm{C}$ in route A. It is assumed that resin temperature dropped down dramatically before injection PP reached to joining area, and molecular diffusion didn't complete.

Additionally, this molecular diffusion could be affected by runner route because the runner distance of route $\mathrm{B}$ (approximately $23.5 \mathrm{~mm}$ ) is quite shorter than route $\mathrm{A}$ (approximately $68.0 \mathrm{~mm}$ ). In case of injection speed of $30 \mathrm{~mm} / \mathrm{s}$, the difference of time was about $0.3 \mathrm{~s}$ by calculation from volume flow rate. Thus, route $\mathrm{B}$ has possibility to keep higher 


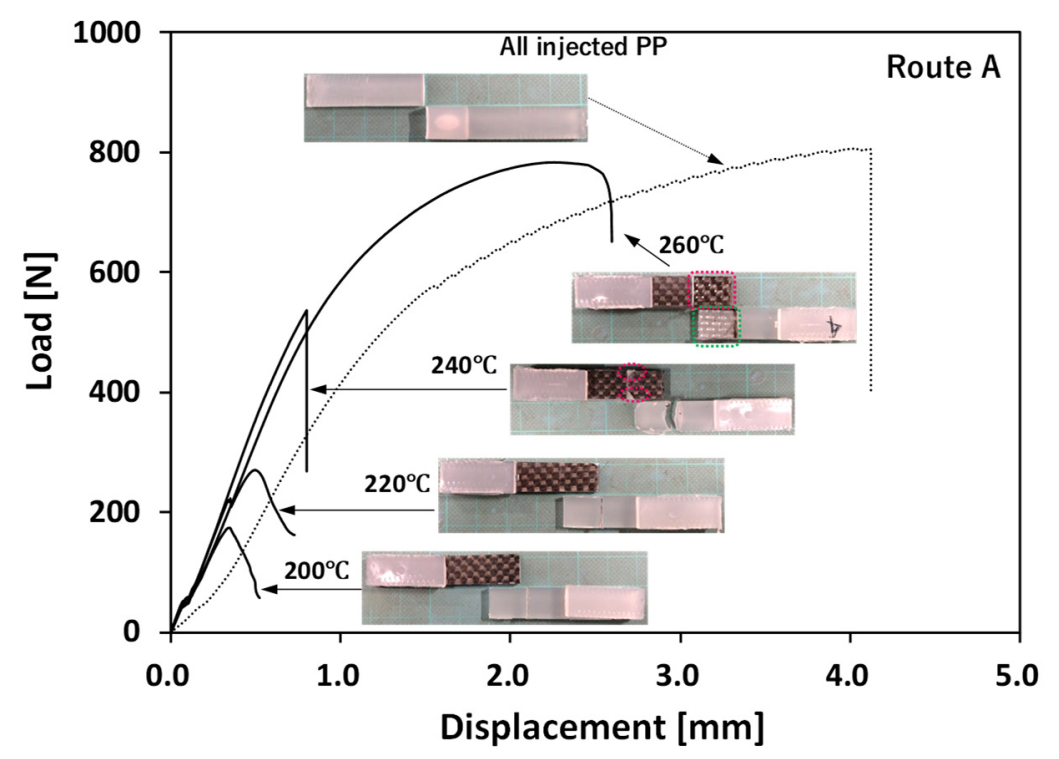

(a)

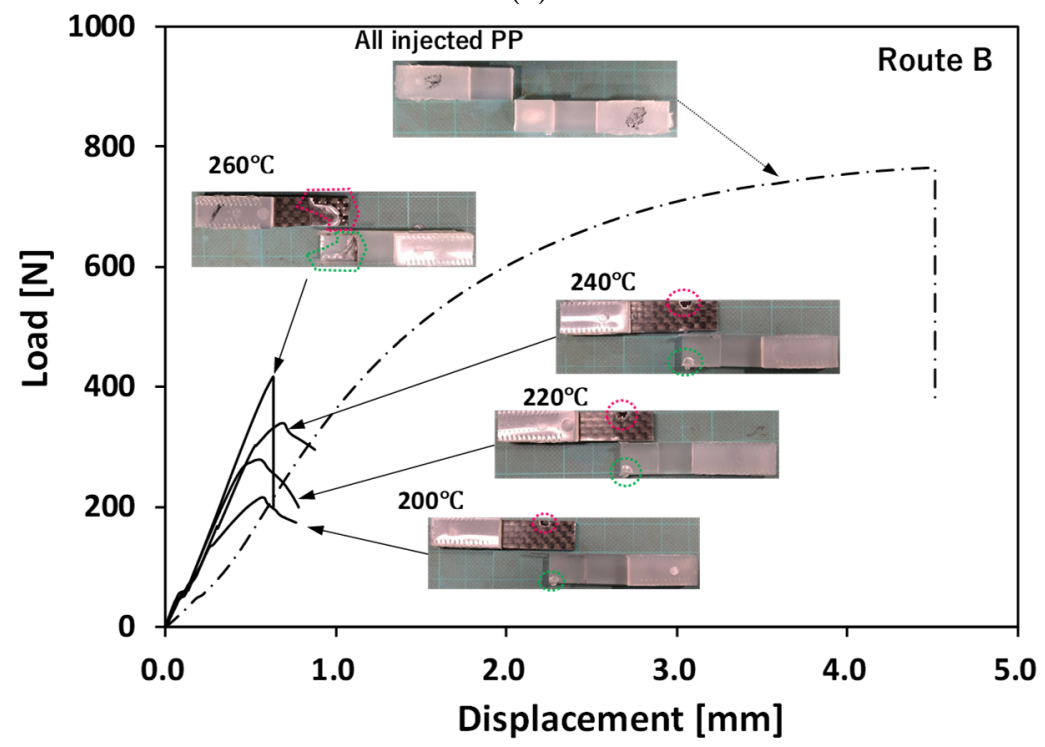

(b)

Figure 3: Load-displacement curve and fracture mode of over-moulded specimens without CNFs. (a) Specimens moulded in route A; and (b) Specimens moulded in route $\mathrm{B}$.

resin temperature at joining area by compared with route A. However, interestingly, increasing rate of failure load in route B was smaller than that in route A by increasing barrel temperature. A part of PP layer in the substrate was peeled at only the entrance of gate position for the conditions at barrel temperature of $200^{\circ} \mathrm{C}, 220^{\circ} \mathrm{C}, 240^{\circ} \mathrm{C}$ through route $\mathrm{B}$. 
Moreover, for the condition at barrel temperature of $260^{\circ} \mathrm{C}$ and route $\mathrm{B}$, the peeled shape was unique as shown in Fig. 3(b). Whereas, the PP layer of joining area was completely peeled at same temperature through route A, as shown in Fig. 3(a).

This reason why, flow behaviour in the mould affected on the lap-shear strength. The velocity field of route A may have the laminar flow while the PP is filled in the mould. Other hands, flow behaviour of route B shows the corner flow. Kimura et al. [18] examined the same influence of runner route, and orientation of glass fibre in injection resin was observed through X-ray tomography. The glass fibres aligned as curve shape along the flow path which melted polymer composites enter from the side of joining area (like route $\mathrm{B}$ in this experiment). Therefore, the peeled shape (at $260^{\circ} \mathrm{C}$, route B) corresponds to flow shape and the diffusion welding did not conduct uniformly. However, route $\mathrm{B}$ has higher failure load at $200^{\circ} \mathrm{C}$ and $220^{\circ} \mathrm{C}$ by compared with route A at same temperature. Thus, the optimization of gate position in route $\mathrm{B}$ could improve the joining strength. From these reasons, keeping high temperature above melt temperature and uniform velocity field for constant temperature distribution during injection moulding should be realized to obtain the excellent lap-shear strength. The resin temperature at joining area is also affected by injection speed. The optimum resin temperature at joining interface should be discussed in the mould during injection moulding by using numerical simulation and in-line seniors in further discussion.

\subsection{Influence of CNF addition on lap-shear strength}

In this section, the influence of CNFs addition on joining strength is discussed. The effect of CNF addition on lap-shear strength may display after molecular diffusion was completed since CNFs exist in the PP layer of substrate. The results of averaged shear strength and displacement at break by adding CNFs were summarized in Fig. 4 for specimens moulded through route A and Fig. 5 for specimens moulded through route $\mathrm{B}$.

In route A (see in Fig. 4), above barrel temperature of $240^{\circ} \mathrm{C}$, lap-shear strength and displacement at break increased by adding CNFs up to $1.0 \mathrm{wt} \%$. By compared with samples without CNFs, the lap-shear strength and displacement at break are improved by $32 \%$ and $54 \%$ respectively at barrel temperature of $240^{\circ} \mathrm{C}$, and those are improved by $12 \%$ and $85 \%$ respectively at barrel temperature of $260^{\circ} \mathrm{C}$. However, by adding CNFs of $3.0 \mathrm{wt} \%$, the lapshear strength and displacement at break were decreased or almost same value. As we already

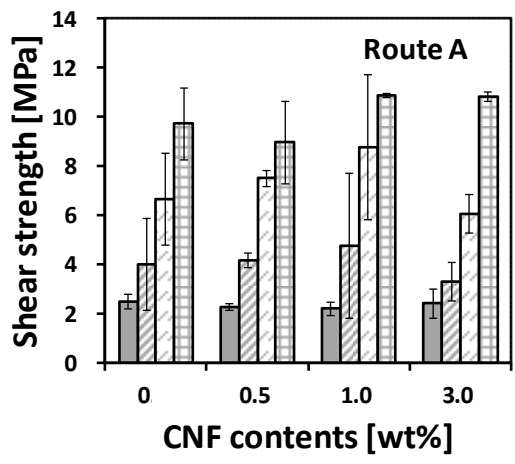

(a)

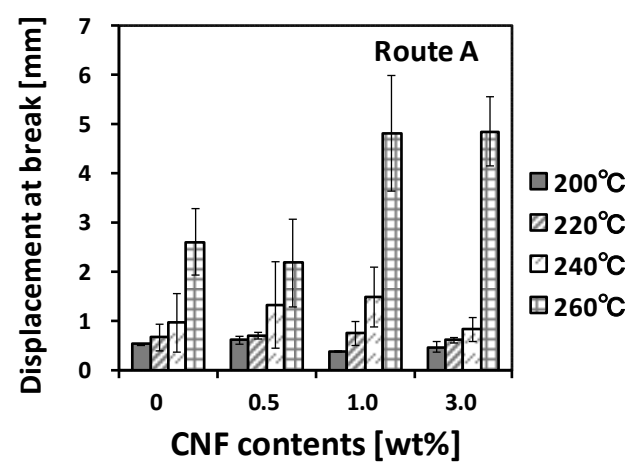

(b)

Figure 4: The results of lap shear test at various CNF loading and barrel temperature through route A. (a) lap-shear strength; (b) displacement at break. 


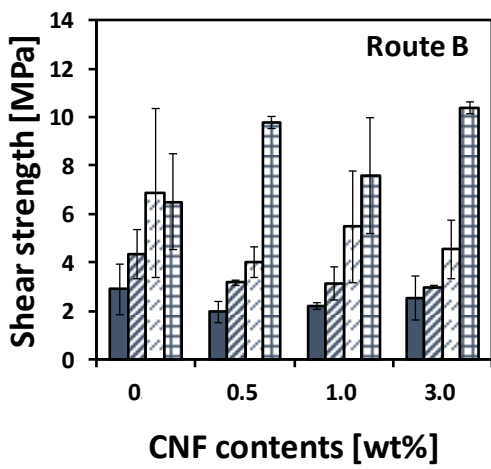

(a)

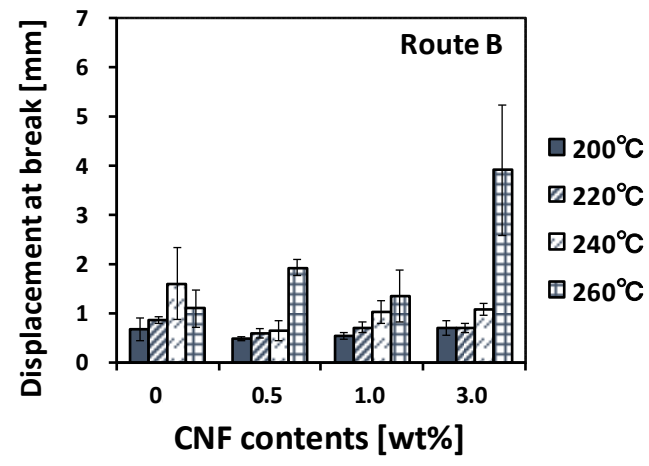

(b)

Figure 5: The results of lap-shear test at various CNF loading and barrel temperature through route B. (a) lap-shear strength; (b) displacement at break.

discussed in our previous work [25], this reason why dispersion state of nanofibers greatly affected on the joining strength. The agglomeration of nanofibers may be weak point during lap-shear test. Therefore, dispersion of CNFs still should be improved during mixing by compounder.

In route B (see in Fig. 5), at only barrel temperature of $260^{\circ} \mathrm{C}$, lap-shear strength and displacement at break increased by adding CNFs up to $3.0 \mathrm{wt} \%$. This result was completely different with result of route A. At that condition, the lap-shear strength and displacement at break were increased by $60 \%$ and $357 \%$ respectively. However, these values were lower than those values in route A at same temperature. This reason was already discussed in Section 3.1, the flow behaviour at joining area affected on molecular diffusion. Thus, CNFs could perform as interconnection role at only partially bonded area, uniform bonding state should be necessary to improve the joining strength. From these results, we found that CNFs have ability to improve the lap-shear strength at specific conditions. The optimum barrel temperature (at least above $240^{\circ} \mathrm{C}$ ) and uniform temperature distribution are necessary to get the interconnection ability of CNFs on joining strength.

Finally, the fracture modes are summarized in Table 2 for route A and Table 3 for route B. The fracture modes were categorized as follows: (a) interfacial failure between substrate and injection resin (i.e., not bonding), (b) partially or fully substrate failure of resin layer, and (c) flexure failure at side of injected PP. The examples of these fracture modes are shown in Fig. 6. The fracture modes are completely linked to lap-shear strength. Especially, at barrel temperature of $260^{\circ} \mathrm{C}$, fracture mode was shifted from type (b) to type (c) with increasing CNF loading. According to fracture type of "all injected PP" samples as shown in Fig. 3, fracture mode of type (c) shows maximum lap-shear strength. Therefore, CNFs absolutely improve the joining strength after polymer diffusion is completely done.

\subsection{Fracture morphology}

The fracture morphology of over-moulded specimens after lap-shear test was observed by FE-SEM. To confirm the presence of CNFs at joining area, the peeled surfaces were observed in samples which were fractured in type (b) in Fig. 6. Fig. 7 shows peeled surfaces of over- 
Table 2: Failure mode of specimens moulded in route A.

\begin{tabular}{|c|c|c|c|c|}
\hline \multirow{2}{*}{ Barrel temp. $\left({ }^{\circ} \mathrm{C}\right)$} & \multicolumn{4}{|c|}{ CNF loading (wt\%) } \\
\cline { 2 - 5 } & 0 & 0.5 & 1.0 & 3.0 \\
\hline 200 & (a) & (a) & (a) & (a) \\
\hline 220 & (a) & (a) & (a) & (a) \\
\hline 240 & (a), (b) & (b) & (b) & (a) \\
\hline 260 & (b) & (b), (c) & (b), (c) & (c) \\
\hline
\end{tabular}

Table 3: Failure mode of specimens moulded in route B.

\begin{tabular}{|c|c|c|c|c|}
\hline \multirow{2}{*}{ Barrel temp. $\left({ }^{\circ} \mathrm{C}\right)$} & \multicolumn{4}{|c|}{ CNF loading (wt\%) } \\
\cline { 2 - 5 } & 0 & 0.5 & 1.0 & 3.0 \\
\hline 200 & (b) & (b) & (b) & (b) \\
\hline 220 & (b) & (b) & (b) & (b) \\
\hline 240 & (b) & (b) & (b) & (b) \\
\hline 260 & (b) & (b), (c) & (b), (c) & (c) \\
\hline
\end{tabular}
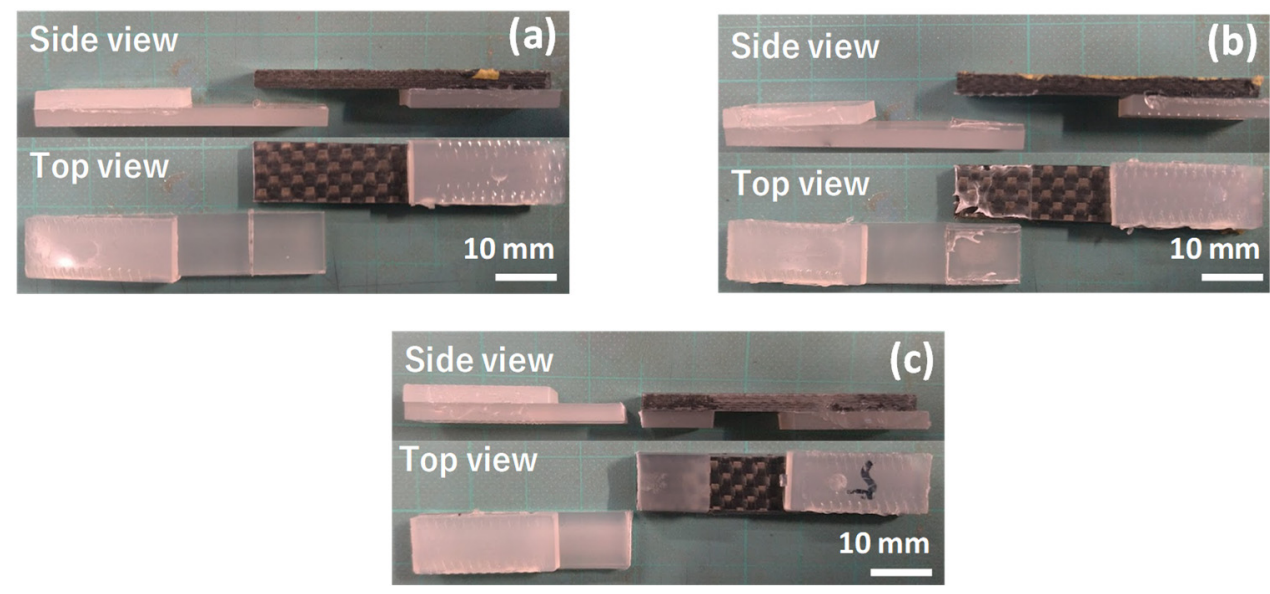

Figure 6: Fracture modes after lap-shear test. (a) Interfacial failure between substrate and injection PP; (b) Substrate failure of resin layer; and (c) Flexure failure at injection PP.

moulded sample without CNFs that moulded at barrel temperature of $260^{\circ} \mathrm{C}$ through route A on the both side (i.e. substrate side and injected PP side). At the aperture of plain weave in substrate part, the PP was confirmed and deformed along the shear direction. Moreover, the shear deformation of PP was confirmed on the side of injection PP as well. The PP is impregnated well to CFs and good joining state was confirmed from Fig. 7.

Other hands, the over-moulded specimen with containing CNFs of $0.5 \mathrm{wt} \%$ (moulded at $240^{\circ} \mathrm{C}$, route A) has completely different fracture morphology as shown in Fig. 8. In the PP at aperture of cloth and gaps between CFs at substrate part, CNFs are confirmed among the $\mathrm{PP}$ at high magnification. The CNFs may restrict the PP deformation by CNF networks since 


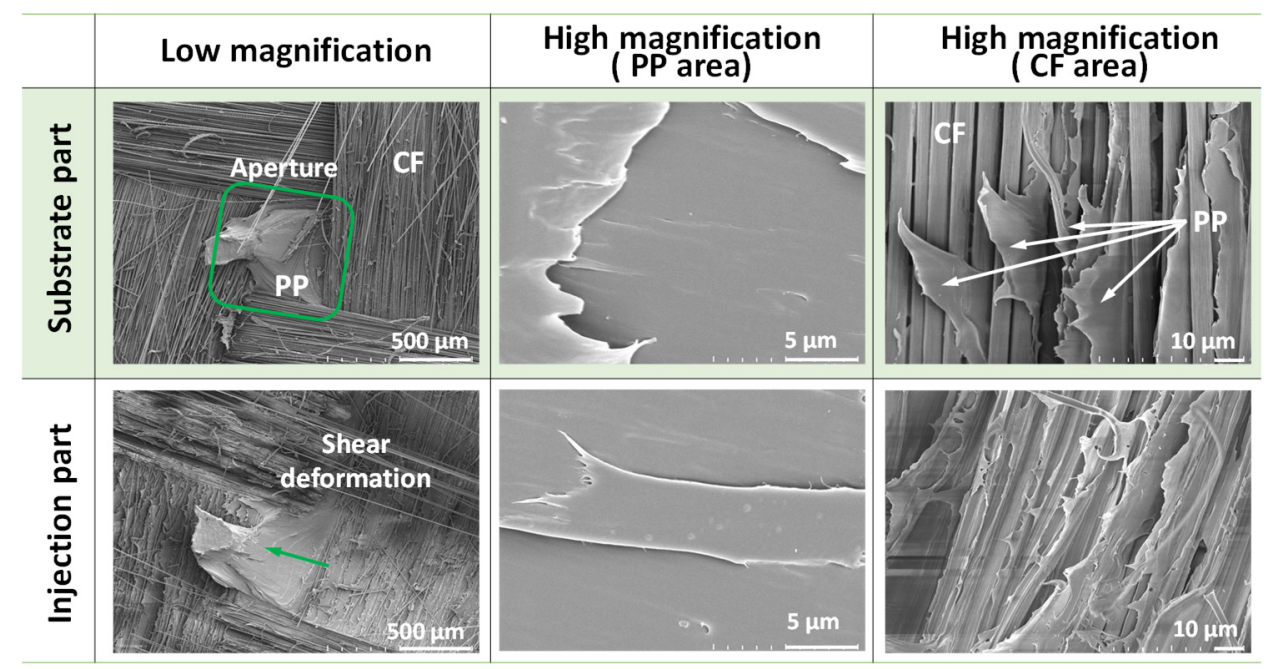

Figure 7: Fracture morphology of peeled surface on the substrate part (upper) and injection part (lower) for over-moulded sample without $\mathrm{CNFs}$ (moulded at $260^{\circ} \mathrm{C}$, route A).

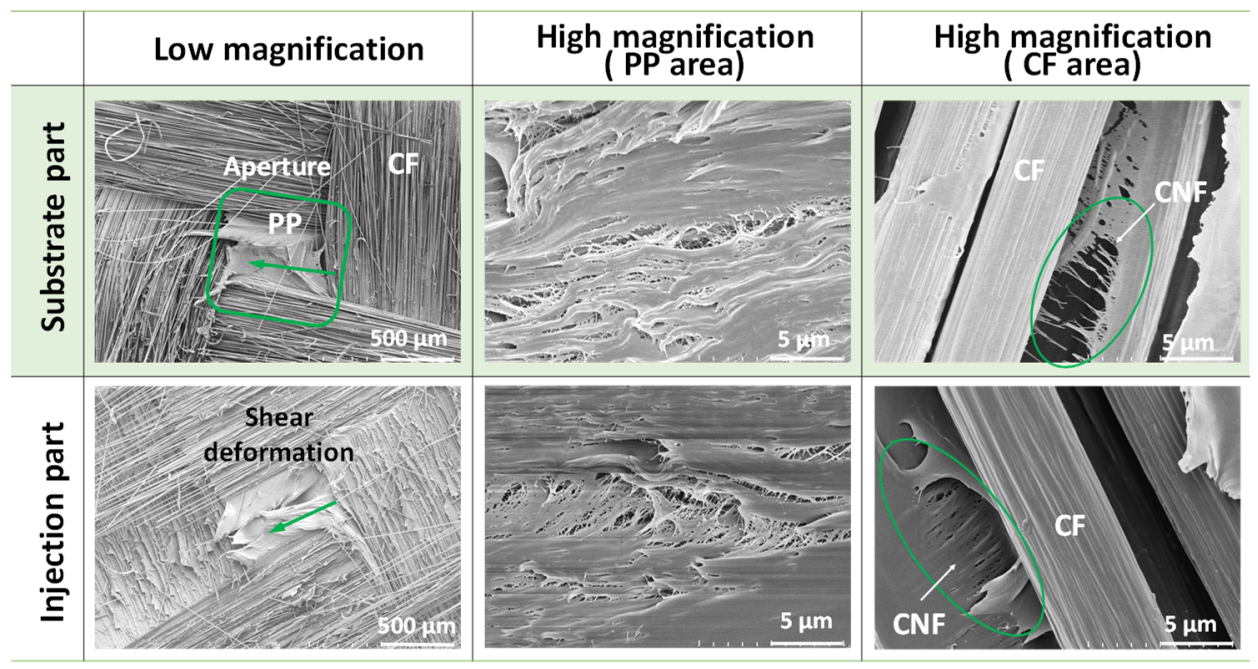

Figure 8: Fracture morphology of peeled surface on the substrate part (upper) and injection part (lower) for over-moulded sample with $\mathrm{CNF}$ of $0.5 \mathrm{wt} \%$ (moulded at $240^{\circ} \mathrm{C}$, route $\mathrm{A})$.

deformation length of PP at aperture decreased by adding CNFs. Surprisingly, the CNFs could confirm on the both sides even though CNFs added on only surface of substrate part. This proves that CNFs reinforce the PP at joining area and have interconnection role during shear deformation by lap-shear test. Thus, the CNF addition may improve the apparent shear strength of joining area by this mechanism. 


\section{CONCLUSIONS}

In this paper, we newly adopt CNFs at joining interface for improving joining strength through injection over-moulding. The joining strength was determined as apparent lap-shear strength of single-lap joint. The barrel temperature and runner route were varied for moulding the lap joint specimens in terms of resin temperature at joining area. As a result, lap-shear strength significantly increased as increasing barrel temperature due to promoting molecular diffusion of PP between resin layer of substrate and injection resin. In the influence of runner route on lap-shear strength, route A shows higher strength by compared with route $\mathrm{B}$ at barrel temperature of $240^{\circ} \mathrm{C}$ and $260^{\circ} \mathrm{C}$, even though route B could carry melt PP to joining area with keeping higher resin temperature. This assumed that the flow behaviour of route $\mathrm{B}$ may show the corner flow, and the temperature distribution at joining area was inhomogeneous. Thus, the homogeneous flow behaviour and temperature distribution are necessary to improve lap-shear strength. However, the optimization of process parameters is necessary to get the enough temperature for fusion welding.

In the effect of CNF addition at joining interface, lap-shear strength and displacement at break significantly increased by adding the CNFs against the specific conditions. The reinforcement effect of CNFs exhibited above barrel temperature of $240^{\circ} \mathrm{C}$ in route A and barrel temperature of $260^{\circ} \mathrm{C}$ in route B, respectively. Finally, maximum lap-shear strength was $10.9 \mathrm{MPa}$ in this experiment at the condition of CNF loading of $1.0 \mathrm{wt} \%$ and barrel temperature of $260^{\circ} \mathrm{C}$ in route A. By morphology assessment, CNFs could confirm at the both peeled surfaces. CNFs restrict the movement of PP molecular chain during shear deformation, and CNFs reinforce the fusion welded PP between injection resin and resin layer of substrate. In the future, resin temperature of joining area during over-moulding should be discussed more to obtain the maximum effect of CNF addition.

\section{REFERENCES}

[1] Schricker, K., Diller, S. \& Bergmann, J.P., Bubble formation in thermal joining of plastics with metals. Procedia CIRP, 74, pp. 518-523, 2018.

[2] Grefe, H., Kandula, M.W. \& Dilger, K., Influence of the fibre orientation on the lap shear strength and fracture behaviour of adhesively bonded composite metal joints at high strain rates. International Journal of Adhesion and Adhesives, 97, 102486, 2020.

[3] Schulz, M., Janssen, H. \& Brecher, C., Adaptive, connected production of hybrid thermoplastic prototypes. Reinforced Plastics, 63(1), pp. 26-28, 2019.

[4] Galvez, P. et al., Study of the behaviour of adhesive joints of steel with CFRP for its application in bus structures. Composites Part B: Engineering, 129, pp. 41-46, 2017.

[5] Ohishi, M., Ohtani, A. \& Nakai, A., Effect of heater system on heating efficiency and interfacial properties between prepreg and injected part in hybrid molding. Journal of Mechanical Engineering and Automation, 7(1), pp. 1-7, 2017.

[6] Blok, L.G., Longana, M.L., Yu, H. \& Woods, B.K.S., An investigation into 3D printing of fibre reinforced thermoplastic composites. Additive Manufacturing, 22, pp. 176186, 2018.

[7] Prüß, H. \& Vietor, T., Design for fiber-reinforced additive manufacturing. The American Society of Mechanical Engineers Journal of Mechanical Design, 137(11), $111409,2015$.

[8] Sugiyama, K., Matsuzaki, R., Ueda, M., Todoroki, A. \& Hirano, Y., 3D printing of composite sandwich structures using continuous carbon fiber and fiber tension. Composites Part A: Applied Science and Manufacturing, 113, pp. 114-121, 2018. 
[9] Holzinger, M., Blase, J., Reinhardt, A. \& Kroll, L., New additive manufacturing technology for fibre-reinforced plastics in skeleton structure. Journal of Reinforced Plastics and Composites, 37(20), pp. 1246-1254, 2018.

[10] Fiorotto, M. \& Lucchetta, G., Experimental investigation of a new hybrid molding process to manufacture high-performance composites. International Journal of Material Forming, 6, pp. 179-185, 2013.

[11] Joppich, T., Menrath, A. \& Henning, F., Advanced molds and methods for the fundamental analysis of process induced interface bonding properties of hybrid, thermoplastic composites. Procedia CIRP, 66, pp. 137-142, 2017.

[12] Jiao, J., Xu, Z., Wang, Q., Sheng, L. \& Zhang, W., CFRTP and stainless steel laser joining: Thermal defects analysis and joining parameters optimization. Optics and Laser Technology, 103, pp. 170-176, 2018.

[13] Li, Y. et al., Effect of laser heat input on the interface morphology during laser joining of CFRTP and 6061 aluminum alloy. Journal of Manufacturing Processes, 50, pp. 366-379, 2020.

[14] Jiao, J. et al., Laser direct joining of CFRTP and aluminium alloy with a hybrid surface pre-treating method. Composites Part B: Engineering, 173, 106911, 2019.

[15] Wu, L.H., Nagatsuka, K. \& Nakata, K., Direct joining of oxygen-free copper and carbon-fiber-reinforced plastic by friction lap joining. Journal of Materials Science and Technology, 34(1), pp. 192-197, 2018.

[16] Goto, K., Imai, K., Arai, M. \& Ishikawa, T., Shear and tensile joint strengths of carbon fiber-reinforced thermoplastics using ultrasonic welding. Composites Part A: Applied Science and Manufacturing, 116, pp. 126-137, 2019.

[17] Lucchetta, G., Marinello, F. \& Bariani, P.F., Aluminum sheet surface roughness correlation with adhesion in polymer metal hybrid overmolding. CIRP Annals, 60(1), pp. 559-562, 2011.

[18] Kimura, F., Kadoya, S. \& Kajihara, Y., Effects of molding conditions on injection molded direct joining under various surface fine-structuring. The International Journal of Advanced Manufacturing Technology, 101, pp. 2703-2712, 2019.

[19] Kimura, F., Kadoya, S. \& Kajihara, Y., Effects of molding conditions on injection molded direct joining using a metal with nano-structured surface. Precision Engineering, 45, pp. 203-208, 2016.

[20] Li, X. et al., Aluminum/polypropylene composites produced through injection molding. Journal of Materials Processing Technology, 255, pp. 635-643, 2018.

[21] Stormonth-Darling, J.M. \& Gadegaard, N., Injection moulding difficult nanopatterns with hybrid polymer inlays. Macromolecular Materials and Engineering, 297, pp. 1075-1080, 2012.

[22] Garcia, E.J., Wardle, B.L., Hart, A.J. \& Yamamoto, N., Fabrication and multifunctional properties of a hybrid laminate with aligned carbon nanotubes grown in situ. Composites Science and Technology, 68(9), pp. 2304-2041, 2008.

[23] Wicks, S.S., de Villoria, R.G. \& Wardle, B.L., Interlaminar and intralaminar reinforcement of composite laminates with aligned carbon nanotubes. Composites Science and Technology, 70(1), pp. 20-28, 2010.

[24] Veedu, V. et al., Multifunctional composites using reinforced laminae with carbonnanotube forests. Nature Materials, 5, pp. 457-462, 2006.

[25] Matsumoto, K., Ishikawa, T. \& Tanaka, T., A novel joining method by using carbon nanotube-based thermoplastic film for injection over-molding process. Journal of Reinforced Plastics and Composites, 38(13), pp. 616-627, 2019. 